
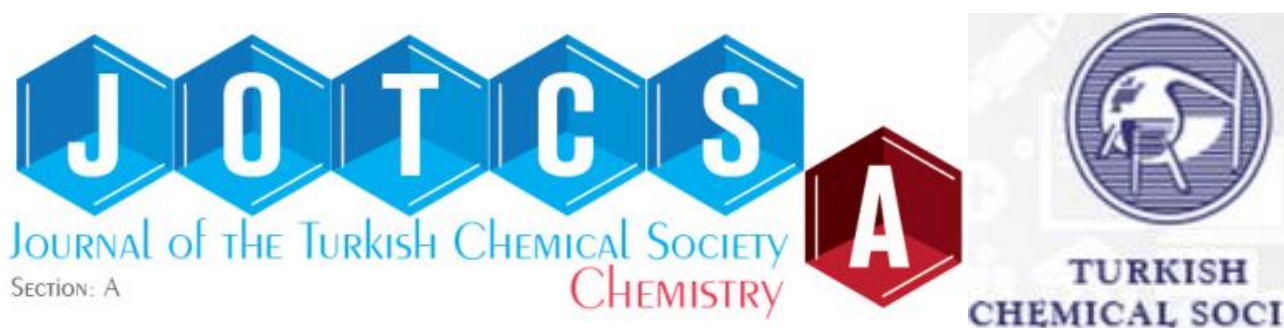

TURKISH

CHEMICAL SOCIETY

\title{
Synthesis of Thiazole Derivatives as Antimicrobial Agents by Green Chemistry Techniques
}

\author{
Serpil Demirci ${ }^{1}$ \\ 1 Giresun University, Vocational High School of Health Services Department of Medical \\ Services and Techniques, 28100, Giresun, Turkey.
}

\begin{abstract}
Amines (2) and (26) were obtained from the condensation of the corresponding amines with 3,4-difluoronitrobenzene. The reduction of nitro group produced the corresponding amines (3 and 27). The synthesis of esters $(\mathbf{7}, \mathbf{1 2}, \mathbf{1 9}, \mathbf{2 8})$ was carried out from the treatment of the amines, $(\mathbf{1}, \mathbf{3}, \mathbf{1 8}, \mathbf{2 7})$ with ethyl bromoacetate, then these compounds were converted to the corresponding hydrazides $(\mathbf{8}, \mathbf{1 3}, \mathbf{2 9})$ by the treatment with hydrazine hydrate. The triazole was obtained from the intramolecular cyclisation of the corresponding carbothioamide in basic media and this compound was then converted to the morpholine-triazole-penicillin hybrid by a mannich reaction. The cyclocondensation of hydrazine carbothioamides $(\mathbf{9 b}, \mathbf{1 4}, \mathbf{2 1})$ or urea (4) with 2-bromo-1-(4-chlorophenyl)ethenone generated the thiazole derivatives. On the other hand, the treatment of $\mathbf{4}, \mathbf{9 b}$, and $\mathbf{1 4}$ with ethyl bromoacetate yielded 4-oxo-1,3thiazolidines $(\mathbf{6}, \mathbf{1 1}, \mathbf{1 6})$. Three methods containing conventional, microwave, and ultrasoundmediated techniques were applied. Best results were assessed using microwave- and ultrasoundpromoted procedures. The structures of the newly synthesised compounds were elucidated by spectroscopic techniques, and the antimicrobial activity screening studies were also performed. Some of them exhibited good to moderate activity on the test bacteria.
\end{abstract}

Keywords: Antimicrobial activity, microwave, imidazole, morpholine, green chemistry.

Submitted: January 06, 2018. Accepted: February 16, 2018.

Cite this: Demirci S. Synthesis of Thiazole Derivatives as Antimicrobial Agents by Green Chemistry Techniques. JOTCSA. 2018;5(2):393-414.

DOI: $\underline{\text { http://dx.doi.org/10.18596/jotcsa.375716. }}$

*Corresponding author. E-mail: demirciserpil17@gmail.com. Tel/Fax: ++90-507-9234321, +90-454-310-2932. 
Demirci. JOTCSA. 2018; 5(2): 393-414.

\section{INTRODUCTION}

Although humans are accustomed to fighting with the invasion of such pathogens with both inherent defenses as well as medical protections, many bacteria succeed to get rid of our immunities and are resistant to most of synthetic or natural antibiotics caused by the excessive and prolonged use of currently available antibiotics, and this made microbial infections one of the foremost health crises worldwide.

Literature survey reveals that bacterial infections cause to hundreds of thousands of deaths annually and billions of dollars in healthcare expenses emphasizing the urgent need to constant push to discover and improve strategies to counter these threats (1-5). Molecular hybridization is one of the mostly referenced strategy aiming to overcome bacterial resistance involving the integration of two or more pharmacophoric subunits from molecular structure of previously reported bioactive molecules in one framework. The expected features from the newly designed architecture are having improved activity and efficacy than the parent compounds with less tendency to resistance, reduced side effects with maintaining the desired properties of the original version (6). In the studies aiming the discovery of new drug candidates, the combination of bioactive structural motifs in a single skeleton improving the overall biological efficacy has become the widely applied strategy (7).

Azoles are accepted as immensely important members of heterocyclic class of organic compounds since their existence in a number of synthetic or natural products with biological activity as privileged pharmacophores (8). Among these, imidazole scaffold constitutes a major pharmacophoric group responsible antifungal activity. Imidazole containing antifungal drugs such as econazole, miconazole, clotrimazole, ketoconazole, oxiconazole, sulconazole, etc control fungal infections by blocking ergosterol biosynthesis which is an essential component of fungal cell wall (8-11). Imidazole core constitutes also a part some of other the clinically used drugs such as acetomidate, cimetidine, omeprazole, lansoprazole, azomycine, flumazenil, thyroliberin, methimazole, acting as a pharmacophoric group or a substituent. Furthermore, the existence of imidazole nucleus in the structure of a bioactive agent may be preferable for increasing solubility in water. Due to this reason, the introduction of imidazole unit to a synthetic or natural product has become a frequently referenced methodology aiming to improve bioactivity $(11,12)$. Moreover, imidazoles constitute a main structural unit of some biomolecules in human organisms including histidine, vitamin B12, histamine, and biotin. Another biomolecule Ribotide possessing 4(5)-aminoimidazole-5(4)-carboxamide structure acts as a key compound in the biosynthesis of natural purine component of RNA and DNA (11). 
Demirci. JOTCSA. 2018; 5(2): 393-414.

Another azole nucleus, thiazolidinone unit constitutes the core structure of a number of natural biomolecules, drugs and synthetic bioactive compounds possessing antimicrobial, antifungal, anticancer, and antidiabetic activity and is of considerable attention (7).

In the recent years, the literature has been enriched with progressive studies on the preparation and biological activities of morpholine derivatives (13). The morpholine unit has been extensively used in the drug design studies since its presence in the structure of a bioactive compound can supply some improvements in the pharmacokinetics. It constitutes functional unit of nearly 19 drugs approved by FDA. Linezolid, which is an oxazolidinone class antibacterial drug, contains a morpholine subunit in its structure. Moreover, The World Drug Index contains well over 100 drugs including a morpholine unit as a core scaffold, a capping fragment or a component in a hybrid system (14). Furthermore, some morpholine derivatives have been reported as anticancer, antifungal, antibacterial and antihypertensive agents. Some representative examples of bioactive morpholines are presented. The major structural feature doing morpholine ring so popular is the inclusion an oxygen, which forms a strong complex with its target participating in donor-acceptor type interactions with the substrate. Furthermore, oxygen displays a pharmacophoric feature by decreasing the basicity of nitrogen. In addition, if the nucleus is linked to a lipophilic skeleton, it improves the bioavailability of bioactive compound in oral administration by enhancing its solubility in water (15-19).

In recent years, the application of green methodologies has aroused as more efficient techniques environmentally. Compared with conventional methods, eco-friendly procedures have some advantages including decreased reaction time, improved yields, ease of work-up and isolation of products. Furthermore, polar and aprotic solvents which are often expensive, toxic and difficult to remove, are environmental pollutants.

Since these reasons, the focus has now shifted to eliminate or minimise the use of organic solvents with solvent-free methodologies yielding pure products with high yields. The application of microwave mediated procedures for the synthesis of organic compounds has supplied an efficient, safe, and ecofriendly technique with shorter reaction time $(20,21)$.

Sonication technique constitutes another methodology which supply clean and environmentally harmless procedure leading to the formation of bioactive compounds. In most of cases, the application of this method has led to take place organic reactions with higher yields and shorter reaction times $(22,23)$.

It is accepted that both two methods have their own advantages. Although microwaves supply fast and appropriate heating for synthetic procedures, it has some limitations in mass transfer. On the other hand, ultrasonic irradiation provides strong physical mixing by cavitation but lacks 
Demirci. JOTCSA. 2018; 5(2): 393-414.

the ability to provide or induce high thermal energy leading to reaction (24). Even so, sonication has been applied successfully in many of organic reactions providing enhancement of reactions rates and yield as well as modification of the reaction pathway, greater selectivity, simplicity of operation, and energy-saving protocols. (25). Moreover, this way has led to develop a simple purification process suitable with the concept of green chemistry $(26,27)$.

Continuing our efforts on the synthesis of novel antibacterial compounds, here we designed novel hybrid molecules including several heterocyclic units with biological activity. The in vitro antibacterial activity screening studies were carried towards some selected Gram (+) and Gram (-) bacteria and yeast like fungi. The effect of microwave and ultrasonic irradiations on the synthetic procedures was investigated as well.

\section{MATERIALS AND METHODS}

All chemicals were purchased from Fluka Chemie AG Buchs (Switzerland) and used without further purification. Melting points of the synthesised compounds were determined in open capillaries on a Büchi B-540 melting point apparatus and are uncorrected. Reactions were monitored by thin-layer chromatography (TLC) on silica gel 60 F254 aluminium sheets. The mobile phase was ethyl acetate: diethyl ether $(1: 1, v: v)$, and detection was made using UV light. FT-IR spectra were recorded using a Perkin Elmer 1600 series FTIR spectrometer. ${ }^{1} \mathrm{H}$ NMR and ${ }^{13} \mathrm{C}$ NMR spectra were recorded in DMSO-d6 on a BRUKER AVENE II $400 \mathrm{MHz}$ NMR Spectrometer (400.13 MHz for ${ }^{1} \mathrm{H}$ and $100.62 \mathrm{MHz}$ for ${ }^{13} \mathrm{C}$ ). The chemical shifts are given in ppm relative to $\mathrm{Me}_{4} \mathrm{Si}$ as an internal reference, $\mathrm{J}$ values are given in $\mathrm{Hz}$. Microwave and ultrasound-mediated syntheses were carried out using monomode CEM-Discover microwave apparatus and Bandelin Sonorex Super RK102H ultrasonic bath, respectively. The elemental analysis was performed on a Costech Elemental Combustion System CHNS-O elemental analyzer. All the compounds gave $\mathrm{C}, \mathrm{H}$ and $\mathrm{N}$ analysis within $\pm 0.4 \%$ of the theoretical values. The Mass spectra were obtained on a Quattro LC-MS (70 eV) Instrument.

\section{General method for the preparation of compounds 2, 26}

Method 1. To a solution of 3-(1H-imidazol-1-yl)propan-1-amine (for 2) or 2-morpholino ethanamine (for 26) $(10 \mathrm{mmol}$ ) in dry acetonitrile, 3,4-difluoronitrobenzene (10 $\mathrm{mmol})$ were added dropwise at $0-5{ }^{\circ} \mathrm{C}$, temperature was then allowed to reach to room temperature and the reactions were maintained for $10 \mathrm{~h}$ until TLC showed completion. The solvent was evaporated under reduced pressure and the obtained solid was recrystallised from an appropriate solvent to give the target product. Method 2. The mixture of 3-(1H-imidazol-1-yl)propan-1-amine (10 $\mathrm{mmol}$ ) and 3,4-difluoronitrobenzene $(10 \mathrm{mmol})$ were irradiated in monomode microwave reactor in closed vessel with pressure control at $100 \mathrm{~W}$ (for 2) or $100 \mathrm{~W}$ (for 26), for 8-10 min. Method 3. The mixture of 3-(1H-imidazol-1-yl)propan-1-amine (for 2 ) or 2-morpholinoethanamine (for 
Demirci. JOTCSA. 2018; 5(2): 393-414.

26) $(10 \mathrm{mmol})$ and 3,4 -difluoronitrobenzene $(10 \mathrm{mmol})$ was sonicated at $45-70 \mathrm{kHz}, 25^{\circ} \mathrm{C}$ for 5-30 min.

\section{General method for the preparation of compounds 3 and 27}

Method 1. Hydrazine hydrate $(25 \mathrm{mmol}$ ) was added to a solution of compound 2 (for $\mathbf{3}$ ) or 26 (for 27 ) (10 mmol) in 1-butanol containing $\mathrm{Pd} / \mathrm{C}(1 \mathrm{mmol})$ and the mixture was allowed to reflux in an oil bath for $12 \mathrm{~h}$. catalyst was removed by filtration on celite, the solvent was removed under reduced pressure, and the obtained crude product was purified by thin layer chromatography $(20 \times 20 \mathrm{~cm}$. normal phase silica-coated glass plate $60 \mathrm{~F} 254$, ethyl acetate:chloroform (3:1), $100 \mathrm{~mL})$. Method 2. The mixture of hydrazine hydrate $(25 \mathrm{mmol})$, $\mathrm{Pd} / \mathrm{C}(1 \mathrm{mmol}$ ) and compound $\mathbf{2}$ (for $\mathbf{3}$ ) or $\mathbf{2 6}$ (for $\mathbf{2 7}$ ) (10 mmol) in 1-butanol was irradiated in a monomode microwave reactor with pressure control in closed vessel at $200 \mathrm{~W}, 150{ }^{\circ} \mathrm{C}$ for 8 $30 \mathrm{~min}$. Catalyst was removed by filtration on celite and the solvent was removed under reduced pressure and the obtained crude product was purified by thin layer chromatography $(20 \times 20 \mathrm{~cm}$. normal phase silica-coated glass plate 60 F254, ethyl acetate-chloroform (3:1), $100 \mathrm{~mL}$ ). Method 3. The mixture of hydrazine hydrate $(25 \mathrm{mmol}), \mathrm{Pd} / \mathrm{C}(1 \mathrm{mmol})$ and compound 2 (for 3) or 26 (for 27) (10 mmol) in 1-butanol was sonicated at $70 \mathrm{kHz}, 25^{\circ} \mathrm{C}$ for $5-35 \mathrm{~min}$. the catalyst was removed by filtration on celite, the solvent was removed under reduced pressure, and the obtained crude product was purified by thin layer chromatography $(20 \times 20 \mathrm{~cm}$. normal phase silica-coated glass plate 60 F254, ethyl acetate-chloroform (3:1), $100 \mathrm{~mL}$ ).

\section{General method for the preparation of compounds $4,9 a, 9 b, 14,21$}

Method 1. The solution of the corresponding compounds $\mathbf{3}, \mathbf{8}, \mathbf{1 3}$ or $\mathbf{2 0}(10 \mathrm{mmol})$ in dry dichloromethane was stirred with benzyl- or phenylisothiocyanate at room temperature for 12$20 \mathrm{~h}$. The solvent was evaporated under reduced pressure and the obtained solid was recrystallised from an appropriate solvent to give the target product. Method 2. The mixture of the corresponding compound 3, 8, 13 or $20(10 \mathrm{mmol})$ and benzyl- or phenylisothiocyanate was irradiated in a monomode microwave reactor in closed vessel with the pressure control at $150 \mathrm{~W}, 100^{\circ} \mathrm{C}$ for $15 \mathrm{~min}$. The obtained solid was purified by crystallization from an appropriate solvent to give the target product. Method 3. The mixture of the corresponding compound 3, 8,13 or $20(10 \mathrm{mmol})$ and benzyl- or phenylisothiocyanate was sonicated at $60-70 \mathrm{kHz}, 35^{\circ} \mathrm{C}$ for $15 \mathrm{~min}$. The obtained solid was purified by crystallization from an appropriate solvent to give the target product.

\section{General method for the synthesis of compounds 6, 11 and 16}

Method 1. Ethyl bromoacetate $(10 \mathrm{mmol})$ was added to a solution of the corresponding carbothioamide (4, 9b and $\mathbf{1 4})(10 \mathrm{mmol})$ in absolute ethanol and the mixture was refluxed in the presence of dried sodium acetate $(20 \mathrm{mmol})$ for $16-18 \mathrm{~h}$. The mixture was then cooled to room temperature, poured into ice-cold water while stirring, and left overnight in cold. The solid 
Demirci. JOTCSA. 2018; 5(2): 393-414.

formed was filtered off, washed with water 3 times, and recrystallised from an appropriate solvent to afford the desired compound. Method 2. The mixture of ethyl bromoacetate (10 $\mathrm{mmol})$, the corresponding carbothioamide $(10 \mathrm{mmol})$ and dried sodium acetate $(20 \mathrm{mmol})$ was irradiated in a monomode microwave reactor with pressure control at $100 \mathrm{~W}, 100{ }^{\circ} \mathrm{C}$ for $12 \mathrm{~min}$. The mixture was then poured into ice-cold water while stirring, and left overnight in cold. The formed solid was filtered off, washed with water 3 times, and recrystallised from an appropriate solvent to afford the desired compound. Method 3. The mixture of ethyl bromoacetate (10 $\mathrm{mmol})$, the corresponding carbothioamide $(10 \mathrm{mmol})$ and dried sodium acetate $(20 \mathrm{mmol})$ was sonicated at $50 \mathrm{kHz}, 30^{\circ} \mathrm{C}$ for $15 \mathrm{~min}$. The mixture was then poured into ice-cold water while stirring, and left overnight in cold. The formed solid was filtered off, washed with water 3 times, and recrystallised from an appropriate solvent to afford the desired compound.

\section{General Method for the Synthesis of Compounds 5, 10, 15 and 22}

Method 1. 2-Bromo-1-(4-chlorophenyl)ethanone $(10 \mathrm{mmol})$ and dried sodium acetate (20 $\mathrm{mmol}$ ) were added to a solution of the corresponding carbothioamine $(\mathbf{4}, \mathbf{9 b}, \mathbf{1 4}, \mathbf{2 1})$ in absolute ethanol, and the mixture was refluxed for 16-18 $\mathrm{h}$. Then, the reaction content was poured into ice-cold water while stirring, and left overnight in the cold. The formed solid was filtered off, washed with water 3 times, and recrystallised from acetone to afford the desired compound. Method 2. 2-Bromo-1-(4-chlorophenyl)ethanone (10 mmol) and dried sodium acetate (20 $\mathrm{mmol}$ ) were added to a solution of the corresponding carbothioamine $(\mathbf{4}, \mathbf{9 b}, \mathbf{1 4}, \mathbf{2 1})$ in absolute ethanol, and the mixture was irradiated in a monomode microwave reactor with pressure control in closed vessel at $150 \mathrm{~W}, 80^{\circ} \mathrm{C}$ for $15 \mathrm{~min}$. Then, the reaction content was poured into ice-cold water while stirring, and left overnight in the cold. The formed solid was filtered off, washed with water 3 times, and recrystallised from acetone to afford the desired compound. Method 3. 2Bromo-1-(4-chlorophenyl)ethanone $(10 \mathrm{mmol})$ and dried sodium acetate $(20 \mathrm{mmol})$ were added to a solution of the corresponding carbothioamine $(\mathbf{4}, \mathbf{9 b}, \mathbf{1 4}, \mathbf{2 1})$ in absolute ethanol, and the mixture was sonicated at $60 \mathrm{kHz}, 25^{\circ} \mathrm{C}$ for $18 \mathrm{~min}$. Then, the reaction content was poured into ice-cold water while stirring, and left overnight in the cold. The formed solid was filtered off, washed with water 3 times, and recrystallised from acetone to afford the desired compound.

\section{General Method for the Synthesis of Compounds 7, 12, 19 and 28}

Method 1. Ethyl bromoacetate $(10 \mathrm{mmol})$ was added to a mixture of the corresponding compound 1, 3, 18 or 27 (10 mmol) in dry tetrahydrofuran dropwise at $0-5{ }^{\circ} \mathrm{C}$. Then, the reaction mixture was allowed to reach room temperature and stirred for 16-24 $\mathrm{h}$ in the presence of triethylamine $(10 \mathrm{mmol})$. The precipitated triethylammonium salt was removed by filtration and the resulting solution was evaporated under reduced pressure to dryness. Then the acetonitrile was removed using a rotary evaporator and the obtained crude product was purified by thin layer chromatography $(20 \times 20 \mathrm{~cm}$. normal phase silica-coated glass plate $60 \mathrm{~F} 254$, ethyl acetate-chloroform (3:1), $100 \mathrm{~mL}$ ). Method 2. Ethyl bromoacetate (10 mmol) was added to the 
Demirci. JOTCSA. 2018; 5(2): 393-414.

mixture of the corresponding compounds $\mathbf{1}, \mathbf{3 , 1 8}$ or $27(10 \mathrm{mmol})$ in dry tetrahydrofuran dropwise at $0-5^{\circ} \mathrm{C}$. Then, the reaction mixture was irradiated in a monomode microwave reactor with pressure control in closed vessel corresponding to $80 \mathrm{~W}, 50^{\circ} \mathrm{C}$ for $18 \mathrm{~min}$. The precipitated triethylammonium salt was removed by filtration and the resulting solution was evaporated under reduced pressure and the obtained crude product was purified by thin layer chromatography $(20 \times 20 \mathrm{~cm}$. normal phase silica-coated glass plate $60 \mathrm{~F} 254$, ethyl acetatechloroform (3:1, v:v), $100 \mathrm{~mL})$. Method 3. Ethyl bromoacetate (10 mmol) was added to the mixture of the corresponding compound $\mathbf{1}, \mathbf{3}, \mathbf{1 8}$ or $\mathbf{2 7}(10 \mathrm{mmol})$ in dry tetrahydrofuran dropwise at $0-5^{\circ} \mathrm{C}$. Then, the reaction mixture was sonicated at $40 \mathrm{kHz}, 25^{\circ} \mathrm{C}$ for $20 \mathrm{~min}$. The precipitated triethylammonium salt was removed by filtration and the resulting solution was evaporated under reduced pressure and the obtained crude product was purified by thin layer chromatography $(20 \times 20 \mathrm{~cm}$. normal phase silica-coated glass plate $60 \mathrm{~F} 254$, ethyl acetatechloroform $(3: 1, \mathrm{v}: \mathrm{v}), 100 \mathrm{~mL})$.

\section{General method for the synthesis of compounds 8, 13, 20 and 29}

Method 1. Hydrazine hydrate $(25 \mathrm{mmol})$ was added to the solution of the corresponding ester $(\mathbf{7}, \mathbf{1 2}, \mathbf{1 9}$, and 28$)(10 \mathrm{mmol})$ in 1-butanol, and the mixture was heated under reflux for $5 \mathrm{~h}$. On cooling, the reaction mixture to room temperature, a white solid appeared. The crude product was filtered off and recrystallised from ethyl acetate to afford the desired compound. Method 2. The mixture of hydrazine hydrate $(25 \mathrm{mmol})$ and the corresponding ester $(\mathbf{7}, \mathbf{1 2}, \mathbf{1 9}$, and 28) $(10 \mathrm{mmol})$ in $n$-butanol, and the mixture was irradiated in a monomode microwave reactor with pressure control at $200 \mathrm{~W} 150{ }^{\circ} \mathrm{C}$ for $14 \mathrm{~min}$. On cooling, the reaction mixture to room temperature, a white solid appeared. The product obtained was filtered off and used without further purification. Method 3. The mixture of hydrazine hydrate $(25 \mathrm{mmol})$ and the corresponding ester $(\mathbf{7}, \mathbf{1 2}, \mathbf{1 9}$, and $\mathbf{2 8})(10 \mathrm{mmol})$ in $n$-butanol, and the mixture was sonicated at $40-70 \mathrm{kHz}, 50{ }^{\circ} \mathrm{C}$ for $15-20 \mathrm{~min}$. On cooling the reaction mixture to room temperature, a white solid appeared. The product obtained was filtered off and used without further purification.

\section{General method for the synthesis of compounds $17 a-d$ and $25 a-b$}

Method 1. A solution of the corresponding compounds $\mathbf{3}$ or $\mathbf{2 0}(10 \mathrm{mmol})$ in absolute ethanol was refluxed with the suitable aldehyde for $3 \mathrm{~h}$. Then, the reaction content was allowed to reach room temperature, and a solid appeared. This crude product was filtered off and recrystallised from acetone to give the desired compound. Method 2. A mixture of the corresponding compound 3 or $20(10 \mathrm{mmol})$ and the suitable aldehyde in absolute ethanol was irradiated in a monomode microwave reactor with pressure control in closed vessel at $100 \mathrm{~W}, 80^{\circ} \mathrm{C}$ for $8 \mathrm{~min}$. Then, the reaction content was allowed to reach room temperature, and a solid appeared. This crude product was filtered off and recrystallised from acetone to give the desired compound. Method 3. A mixture of the corresponding compound $\mathbf{3}$ or $\mathbf{2 0}(10 \mathrm{mmol})$ and the suitable aldehyde in absolute ethanol was sonicated at $70 \mathrm{kHz}, 30{ }^{\circ} \mathrm{C}$ for $5 \mathrm{~min}$. Then, the reaction 
Demirci. JOTCSA. 2018; 5(2): 393-414.

content was allowed to reach room temperature, and a solid appeared. This crude product was filtered off and recrystallised from acetone to give the desired compound.

\section{3-\{[(2-Morpholinoethyl)amino]methyl\}-4-phenyl-1H-1,2,4-triazole-5(4H)-thione} (23).

Method 1. A solution of compound $21(10 \mathrm{mmol})$ in ethanol:water (1:1, v:v) was refluxed in the presence of $2 \mathrm{M} \mathrm{NaOH}$ for $3 \mathrm{~h}$, and then the resulting solution was cooled to room temperature and acidified to $\mathrm{pH} 7$ with $37 \% \mathrm{HCl}$. The precipitate formed was filtered off, washed with water, and recrystallised from ethanol:water $(1: 1, v: v)$ to afford the desired compound. Method 2. The mixture of $2 \mathrm{M} \mathrm{NaOH}(2,5 \mathrm{~mL})$ and compound 21 (1 mmol) in water was irradiated in monomode microwave reactor in closed vessel with pressure control at $200 \mathrm{~W}$ for $12 \mathrm{~min}$. (hold time). Upon acidification of reaction content to $\mathrm{pH} 7$ with $37 \% \mathrm{HCl}$, a white solid appeared. This crude product was filtered off, washed with water, and recrystallised from ethanol:water $(1: 1, \mathrm{v}: \mathrm{v})$ to afford the desired compound. Method 3. A solution of compound $21(10 \mathrm{mmol})$ in ethanol:water (1:1 v:v) and $2 \mathrm{M} \mathrm{NaOH}$ was sonicated at $70 \mathrm{kHz}, 30^{\circ} \mathrm{C}$ for 15 min. Then, the reaction content was allowed to reach room temperature, and acidified to $\mathrm{pH} 7$ with $37 \% \mathrm{HCl}$. The precipitate formed was filtered off, washed with water, and recrystallised from ethanol:water $(1: 1)$ to afford the desired compound. Recrystallised from butyl acetate: diethyl ether $(2: 1, \mathrm{v}: \mathrm{v})$

\section{3,3-Dimethyl-6-\{[(3-\{[(2-morpholinoethyl)amino $]$ methyl\}-4-phenyl-5-thioxo-4,5- dihydro-1H-1,2,4-triazol-1-yl)methyl]amino\}-7-oxo-4-thia-1-azabicyclo[3.2.0] heptane-2-carboxylic acid (24).}

Method 1. 6-Aminopenicillanic acid (10 mmol) was added into a solution of compound 23 (10 mmol) dry tetrahydrofuran containing $\mathrm{HCl}(50 \% \mathrm{mmol})$ and the mixture was stirred at room temperature in the presence of formaldehyde $(\% 37,30 \mathrm{mmol})$ for $3 \mathrm{~h}$. Then, the solvent was evaporated under reduced pressure and a solid appeared. The crude product was recrystallised from DMF: $\mathrm{H}_{2} \mathrm{O}(1: 3, \mathrm{v}: \mathrm{v})$ solvent to give the desired compound. Method 2 . The mixture of appropriate secondary amine (6-aminopenicillanic acid) $(1 \mathrm{mmol})$, compound $23(1 \mathrm{mmol}) \mathrm{HCl}$ ( $50 \% \mathrm{mmol}$ ) and formaldehyde $(\% 37,3 \mathrm{mmol}$ ) was irradiated in monomode microwave reactor in closed vessel with pressure control at $100 \mathrm{~W}$ for $5 \mathrm{~min}$. The solid obtained was purified by recrystallisation from DMF:H2O $(1: 3, \mathrm{v}: \mathrm{v})$ to give the desired compound. Method 3. 6aminopenicillanic acid $(10 \mathrm{mmol})$ was added into a solution of compound $23(10 \mathrm{mmol})$ dry tetrahydrofuran containing $\mathrm{HCl}(50 \% \mathrm{mmol})$ was sonicated at $40 \mathrm{kHz}, 30{ }^{\circ} \mathrm{C}$ for $10 \mathrm{~min}$. Then, the reaction content was allowed to reach room temperature. The solvent was then evaporated under reduced pressure and a solid appeared. The crude product was recrystallised from DMF: $\mathrm{H}_{2} \mathrm{O}(1: 3)$ solvent to give the desired compound. 
Demirci. JOTCSA. 2018; 5(2): 393-414.

\section{Antimicrobial activity}

The test microorganisms were obtained from the Refik Saydam Hifzissihha Institute (Ankara, Turkey) and were as follows: Escherichia coli (E. coli) ATCC35218, Yersinia pseudotuberculosis (Y. pseudotuberculosis) ATCC911, Pseudomonas aeruginosa (P. aeruginosa) ATCC43288, Enterococcus faecalis(E. faecalis) ATCC29212, Staphylococcus aureus (S. aureus) ATCC25923, Bacillus cereus (B. cereus) 709 Roma, Mycobacterium smegmatis (M. smegmatis) ATCC607, Candida albicans(C. albicans) ATCC60193 and Saccharomyces cerevisiae (S. cerevisia) RSKK 251 which are laboratry strains. All the newly synthesised compounds were weighed and dissolved in DMSO to prepare extract stock solution of $20.000 \mu \mathrm{g} / \mathrm{mL}$.

The antimicrobial effects of the substances were tested quantitatively in respective broth media by using double microdilution and the minimal inhibition concentration (MIC) values $(\mu \mathrm{g} / \mathrm{mL})$ were determined. The antibacterial and antifungal assays were performed in Mueller-Hinton broth (MH) (Difco, Detroit, MI) at pH 7.3 and buffered Yeast Nitrogen Base (Difco, Detroit, MI) at $\mathrm{pH} 7.0$, respectively. The micro dilution test plates were incubated for $18-24 \mathrm{~h}$ at $35^{\circ} \mathrm{C}$. Brain Heart Infusion broth (BHI) (Difco, Detriot, MI) was used for M. smegmatis, and incubated for $48-72 \mathrm{~h}$ at $35^{\circ} \mathrm{C}(31)$. Ampicillin $(10 \mu \mathrm{g})$, strepromicin, and fluconazole $(5 \mu \mathrm{g})$ were used as standard antibacterial, antimicobacterial, and antifungal drugs, respectively. Dimethylsulfoxide with dilution of $1: 10(\mathrm{v}: \mathrm{v})$ was used as solvent control. The results obtained were submitted in Table 2.

\section{Antimicrobial activity}

All compounds were screened for their antimicrobial activities, and the results are presented in Table 2. Compounds with low activity $(\mathbf{3}, \mathbf{1 4}, \mathbf{2 2})$ were not included. Most of the newly synthesised compounds exhibited good to slight activity on some of the test microorganisms. No clear structure-activity relationships could be detected, showing that the antibacterial activity is significantly affected by the structure of the compound.

It is evident from Table 2 that compounds 17c, 24 and 25 exhibited excellent activity on Mycobacterium smegmatis (Ms), a non-typical tuberculosis factor leading to morbidity and mortality with the mic values between $0.24-1.87 \mu \mathrm{g} / \mu \mathrm{L}$. Further, these compounds are more active than standard drug streptomycin with the mic of $4 \mu \mathrm{g} / \mu \mathrm{L}$. Other compounds $\mathbf{2}, \mathbf{9 b}, \mathbf{1 3}$, $\mathbf{2 0}$ and $\mathbf{2 1}$ displayed good-moderate activity on Ms with the mic values varying between 7.13$31.3 \mu \mathrm{g} / \mu \mathrm{L}$. The imine derivatives $17 \mathrm{a}-\mathrm{c}$ demonstrated quite good activity towards the test bacteria with the mic values of $0.24-15.63 \mu \mathrm{g} / \mu \mathrm{L}$. On the other hand, the remaining imine compound 17d, showed moderate activity on Staphylococcus aureus (Sa) with the mic 31.25 $\mu \mathrm{g} / \mu \mathrm{L}$. Five compounds, $\mathbf{8}, \mathbf{1 3}, \mathbf{2 0}, \mathbf{2 5 b}$ and 29 were found to be more active than ampicillin against Pseudomonas aeruginosa $(\mathrm{Pa})$. Among these, compound $\mathbf{2 0}$ also displayed activity towards Yersinia pseudotuberculosis (Yp), and compound 25b towards Yersinia 
Demirci. JOTCSA. 2018; 5(2): 393-414.

pseudotuberculosi (Yp) and Escherichia coli (Ec). In addition to imines 17a-c and 25b, compounds 13, 20, 23 and 28 showed activity on Bacillus cereus (Bc). In fact, the activity of $\mathbf{2 8}$ on BC was better than ampicillin. Compound $\mathbf{2 4}$ demonstrated good activity towards Enterococcus faecalis (Ef) with the mic of $30 \mu \mathrm{g} / \mu \mathrm{L}$. No significant inhibition was observed on yeast like fungi Candida albicans ( $\mathrm{Ca}$ ) and Saccharomyces cerevisiae (Sc).

\section{RESULTS AND DISCUSSION}

In the present study, the conventional and ecofriendly synthesis and antimicrobial activity screening studies of new thiomorpholine derivatives containing different substituents has been intended. The synthetic strategy of the title compounds was outlined in Schemes 1-6. The condensation of both 3-(1H-imidazol-1-yl)propan-1-amine (tryptamine, 1$)$ and 2morpholinoethanamine (18) with 3,4-difluoronitrobenzene under thermal heating and also microwave and ultrasonic irradiation led to the formation of compounds $\mathbf{2}$ and $\mathbf{2 6}$ respectively, which were then subjected to catalytic hydrogenation to yield the corresponding substituted anilines (3 and 27). The reaction was performed under reflux conditions as well as under microwave (MW) and ultrasonic (US) irradiation with a view to maximizing the yield and minimizing the reaction time. Therefore, the yield of the reaction was increased to $83 \%$ however, more substantially, the entire consumption time of starting compounds was reduced from $10 \mathrm{~h}$ with thermal heating to a remarkable 25 min using MW irradiation and 30 min with sonication. The best MW power in terms of yields and product stability was defined as $80 \mathrm{~W}$ and $50{ }^{\circ} \mathrm{C}$ in closed vessel in solvent free media. On the other hand, the maximum power of ultrasonic irradiation was determined as $45 \mathrm{kHz}$ (Table 1). 
Demirci. JOTCSA. 2018; 5(2): 393-414.

Table 1: Microorganisms and their minimum inhibitory concentrations.

\begin{tabular}{|c|c|c|c|c|c|c|c|c|c|}
\hline Comp No & Micro & ganism & nd Min & al Inhil & ry Cor & entratic & $\mu g / \mu L)$. & & \\
\hline & Ec & Yp & $\mathbf{P a}$ & Sa & Ef & Bc & Ms & $\mathbf{C a}$ & Sc \\
\hline 2 & - & - & 500 & 250 & 500 & - & 31.3 & 250 & 250 \\
\hline 4 & - & - & - & 78,8 & - & - & - & - & 39,4 \\
\hline 5 & - & 62.5 & - & 250 & - & 500 & - & - & - \\
\hline 6 & 125 & 125 & - & - & - & - & - & 500 & 250 \\
\hline 7 & - & 125 & - & 62,5 & 62,5 & - & 500 & 500 & - \\
\hline 8 & 32.5 & 62.5 & 62.5 & - & 250 & 62.5 & 125 & - & - \\
\hline $9 a$ & - & - & - & - & - & - & 62,5 & 62,5 & 62,5 \\
\hline $9 b$ & - & - & - & - & - & - & 15,6 & 62,5 & 62,5 \\
\hline 10 & - & - & - & - & - & - & 500 & 62,5 & 31,3 \\
\hline 11 & - & - & - & - & - & - & 225 & 225 & 225 \\
\hline 12 & - & - & - & 28,7 & - & 57,0 & $<7,13$ & - & 456 \\
\hline 13 & 15,6 & 7,8 & 62,5 & 31,3 & 62,5 & 31,3 & 31,3 & 125 & 125 \\
\hline 15 & - & - & - & - & - & - & 250 & 125 & 125 \\
\hline 16 & - & - & - & - & - & - & 525 & 131 & 131 \\
\hline $17 a$ & 1.95 & 15.63 & 7.81 & 7.81 & 3.91 & 15.63 & 125 & - & - \\
\hline $17 \mathrm{~b}$ & 0.98 & 15.65 & - & 1.95 & 1.95 & 3.91 & 62.5 & - & - \\
\hline $17 c$ & 0.24 & 1.95 & 1.95 & 0.49 & 0.98 & 0.98 & $<0.24$ & - & - \\
\hline $17 d$ & 250 & 250 & - & 31.25 & 250 & 125 & - & - & - \\
\hline 19 & - & - & - & - & 250 & - & - & - & - \\
\hline 20 & 31.3 & 15.6 & 31.3 & 31.3 & 62.5 & 31.3 & 15.6 & 125 & 125 \\
\hline 21 & - & - & - & 500 & 250 & 500 & 31.3 & 62.5 & 62.5 \\
\hline 23 & - & - & - & 15.6 & 62.5 & 31.3 & 7.8 & 125 & 125 \\
\hline 24 & 120 & 120 & 120 & 60 & 30 & 60 & 1,87 & 120 & 60 \\
\hline $25 a$ & - & - & - & - & 125 & - & - & 31.3 & - \\
\hline $25 b$ & 15.6 & 31.3 & 15.6 & 31.3 & 31.3 & 31.3 & 0.97 & 125 & 500 \\
\hline 26 & - & - & - & - & - & 250 & - & - & - \\
\hline 27 & - & 500 & - & 62.5 & 62.5 & 62.5 & 62.5 & 500 & 500 \\
\hline 28 & 125 & - & - & 62.5 & - & 4.0 & 62,5 & 250 & 500 \\
\hline 29 & 62.5 & 62.5 & 62.5 & 125 & 250 & 62.5 & 125 & - & - \\
\hline Amp. & 10 & 18 & $>128$ & 10 & 35 & 15 & & & \\
\hline Strep. & & & & & & & 4 & & \\
\hline Flu & & & & & & & & $<8$ & $<8$ \\
\hline
\end{tabular}

Ec: Escherichia coli ATCC 25922, Yp: Yersinia pseudotuberculosis ATCC 911, Pa: Pseudomonas aeruginosa ATCC 27853, Sa: Staphylococcus aureus ATCC 25923, Ef: Enterococcus faecalis ATCC 29212, Bc: Bacilluscereus 702 Roma, Ms: Mycobacterium smegmatis ATCC607, Ca: Candida albicans ATCC 60193, Saccharomyces cerevisiae RSKK 251, Amp.: Ampicillin, Str.: Streptomycin, Flu.: Fluconazole, (): no activity 
Demirci. JOTCSA. 2018; 5(2): 393-414.

Further, the latter two techniques did not require the use of a toxic solvent such as acetonitrile, which was used as reaction solvent in the conventional method. In order to compare the advantages of all three methods namely ultrasound sonication, microwave irradiation, and conventional method, the reduction of nitro group on compound $\mathbf{2}$ and $\mathbf{2 6}$ was performed applying all three techniques. Compared with conventional method, ultrasonic irradiation reduced the reaction time from $600 \mathrm{~min}$ to 5-30 $\mathrm{min}$ and rise the yields from $62-60 \%$ to $83-$ 90. The comparison of the microwave and ultrasonic irradiation showed that the yields were too close to each other and they requested nearly the same reaction time. Therefore, sonication and microwave irradiation allowed a fast, eco-friendly, and effective synthetic procedure. The formation of compounds $\mathbf{2}$ and $\mathbf{2 6}$ was confirmed by recording their FT-IR, ${ }^{1} \mathrm{H} N M R,{ }^{13} \mathrm{C} N M R$, LC-MS spectra and elemental analysis results. Two sharp peaks at 1483, 1330 (for 2) and 15313, 1329 (for 26) confirmed the presence of nitro group. The shifting of these peaks to 3330,3215 (for $\mathbf{3}$ ) and 3336,3223 (for $\mathbf{2 7}$ ) supported the reduction of nitro group to primary amine. ${ }^{1} \mathrm{H}$ NMR spectra of compounds $\mathbf{3}$ and $\mathbf{2 7}$ showed a new $\mathrm{D}_{2} \mathrm{O}$ exchangeable singlet at 4.49 (for $\mathbf{3}$ ) and 4.54 (for 27) ppm which was attributed to amine function in addition to the expected ones from compounds 3 and 27. The molecular ion peak of $[M]$ and/or $[M+1]([M+1]=265.28$, $[M+1]=235.17,[M+1]=270.12,[M]=239.21)$ corresponded to the molecular masses of the compounds 2, 3, 26 and 27.

Compounds 3, 8, 13, 20 were further treated with benzyl- and/or phenyl isothiocyanate to afford the corresponding urea or carbothioamides $(\mathbf{4}, \mathbf{9 a}, \mathbf{9 b}, \mathbf{1 4}, \mathbf{2 1})$. With the intent the optimisation of reaction conditions, MW and US mediated techniques were performed as well and the reaction yielding compound $\mathbf{4}$ was selected as model reaction. Diverse reaction factors were tested on the model reaction and was monitored by TLC (Table 1).

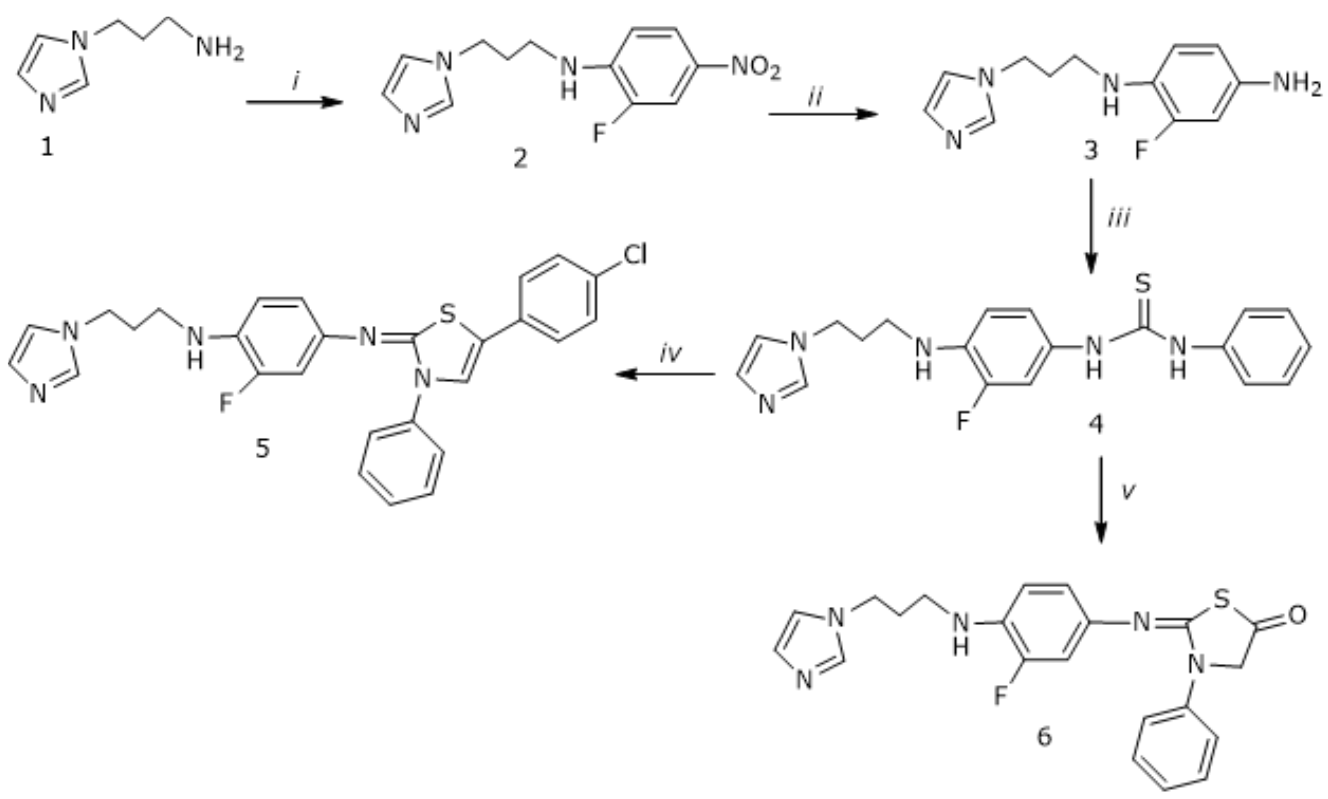

Scheme 1: i: 3,4-difluoronitrobenzene, ii: $\mathrm{NH}_{2} \mathrm{NH}_{2}, \mathrm{Pd} / \mathrm{C}$, iii: phenylisothiocyanate, iv: 2-bromo -1-(4chlorophenyl)ethanone, NaOAc, v: ethylbromoacetate, NaOAc. 
In order to get further improvement for these synthetic procedures, the model reaction was also implemented in different solvents such as $\mathrm{EtOH}, \mathrm{THF}, \mathrm{H}_{2} \mathrm{O}$, and DCM. The results of these analyses indicated that the experiments in solvent led to relatively lower the reaction yield and prolonged reaction time compared with solvent free media in the MW- and US-mediated methods, while dichloromethane was the best solvent in the conventional method at room temperature. Therefore, we next carried out the above model reaction under MW and US irradiation, and the targeted product was obtained in nearly quantitative yield within 5 min. The remaining compounds 4, 9a, 9b,14, and $\mathbf{2 1}$ were obtained under the above optimised conditions. The most prominent peak in ${ }^{13} \mathrm{C}$ NMR spectra of these compounds at $172-183 \mathrm{ppm}$ confirmed the presence of thioamide carbon. The stretching peak derived from this group appeared at 1241-1287 $\mathrm{cm}^{-1}$ in the FT-IR spectra of carbothioamides (4, 9a, 9b, 14, and $\mathbf{2 1}$ ). Further, the carbothiamides except 9 a were cyclised to 1,3-thiazoles $(\mathbf{5}, \mathbf{1 0}, \mathbf{1 5}$, and $\mathbf{2 2})$ by the condensation with 2-bromo-1-(4-chlorophenyl)ethanone under reflux, microwave and ultrasound mediated conditions. Literature findings demonstrated that the synthesis of 1,3thiazole and 1,3-thizolidinone derivatives require the harsh reaction conditions with long reaction times and relatively lower yields and difficult product isolation (28-30).

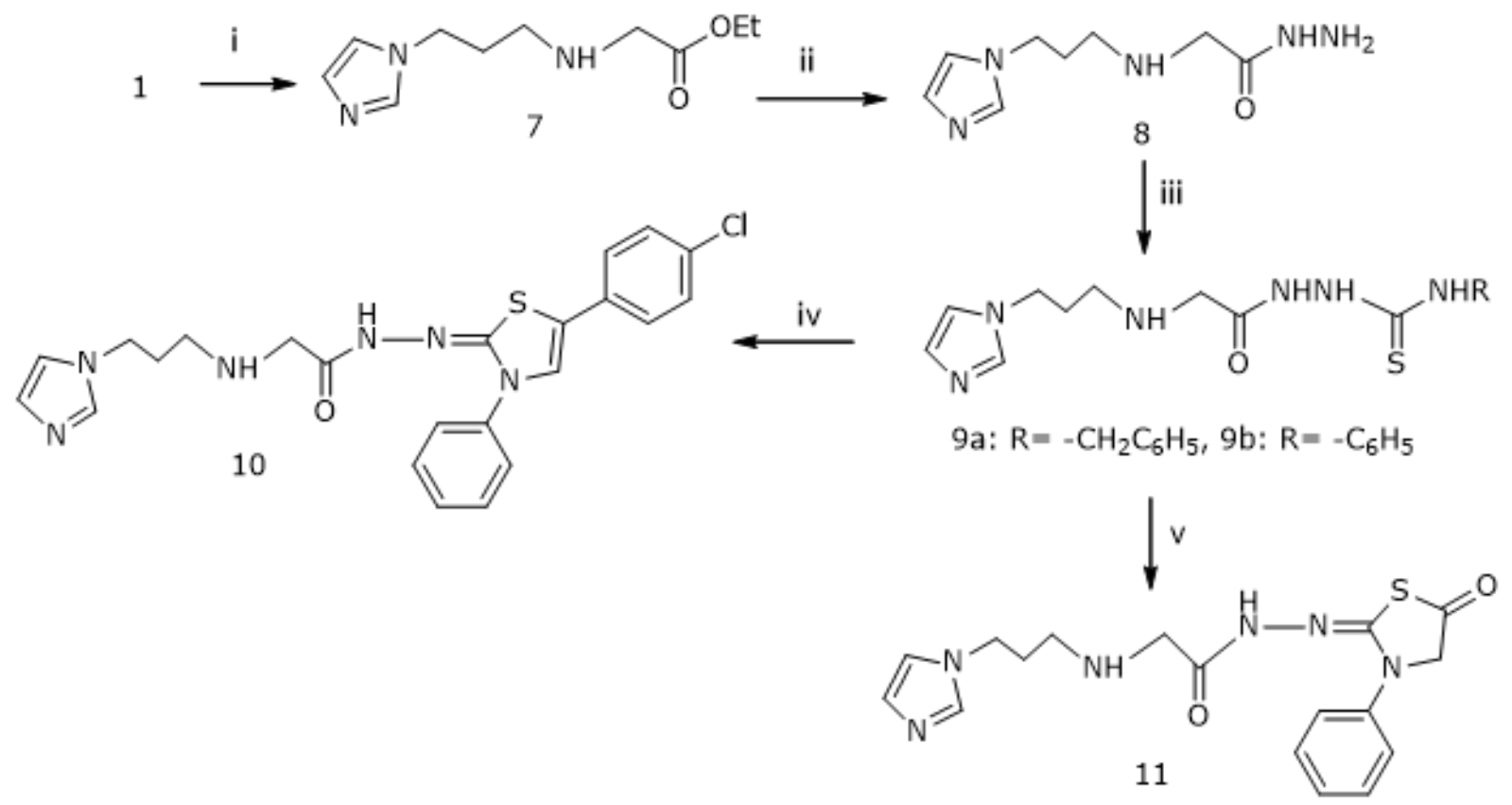

Scheme 2: i: Ethylbromoacetate, triethylamine, ii: $\mathrm{NH}_{2} \mathrm{NH}_{2}$, iii: benzylorethylisothiocyanate, iv: 2-Bromo1-(4-chlorophenyl)ethanone, NaOAc, v: ethylbromoacetate, NaOAc.

The optimisation analyses indicated that $5 \mathrm{~min}$ was the optimal reaction total time at $150 \mathrm{~W}$ maximum MW irradiation with the maximum product formation varying between $89-97 \%$ in ethanol. On the other hand, in the US irradiated method, sonication time was established to be 5-15 min with high yield $(96 \%)$ at $60 \mathrm{kHz}, 25^{\circ} \mathrm{C}$. The formation of 1,3 -thiazoles $(\mathbf{5}, \mathbf{1 0}, \mathbf{1 5}$, and 22 ) was confirmed from the corresponding spectra. With the conversion of thioamides (4, $\mathbf{9 b}, \mathbf{1 4}$, and $\mathbf{2 1})$ to 1,3 -thiazoles $(5, \mathbf{1 0}, \mathbf{1 5}$, and 22 ), the signal belonging to $C=S$ absorption 
Demirci. JOTCSA. 2018; 5(2): 393-414.

disappeared in the FT-IR spectrum, while additional signals derived from C-4 proton of 1,4thiazole ring and 4-chlorophenyl substituent were observed at the related chemical shift values in the ${ }^{1} \mathrm{H}$ NMR spectra.

The ${ }^{13} \mathrm{C}$ NMR spectra of these compounds displayed signals originated from C-4 and C-5 carbons of 1,3-thiazole ring between 117.33-126.18 and 118.26-130.41 ppm as expected. Moreover, the presence of $[\mathrm{M}]^{+}$and/or $[\mathrm{M}+1]^{+}$ion peak in the mass spectrum was in accordance with their molecular weights, and these compounds exhibited reasonable elemental analysis data. The cyclisation of $\mathbf{4}, \mathbf{9 b}$ and $\mathbf{1 4}$ with ethyl bromoacetate generated the corresponding 1,3thiazolidinones $(\mathbf{6}, \mathbf{1 1}$ and $\mathbf{1 6})$.

To optimise MW and US irradiation conditions, compound 6 was selected as the model product, MW and US were implemented at different power values of 100 and $150 \mathrm{~W}$ and ultrasound frequencies of 40 and $50 \mathrm{kHz}$, respectively. The complete consumption of the corresponding compound 4 with best yield was monitored upon microwave irradiation at $80{ }^{\circ} \mathrm{C}$ for 12 min at $100 \mathrm{~W}$ maximum power, while the optimum reaction parameters for sonication were $50 \mathrm{kHz}, 30$ ${ }^{\circ} \mathrm{C}$ and 15 min (Table 1).<smiles>C#CC#Cc1cn(CCCNc2ccc(NCC(=O)NN)cc2F)cn1</smiles>
12 $\downarrow^{13}$<smiles>CC(C)C(C)CNc1ccc(NCCCn2ccnc2)c(F)c1NCC(=O)NNC(=S)NCc1ccccc1</smiles>

Scheme 3.i: Ethylbromoacetate, triethyl amine, ii: $\mathrm{NH}_{2} \mathrm{NH}_{2}$, iii: benzylisothiocyanate,iv: 2-Bromo-1-(4chlorophenyl)ethanone, v:ethyl bromoacetate, NaOAc. 


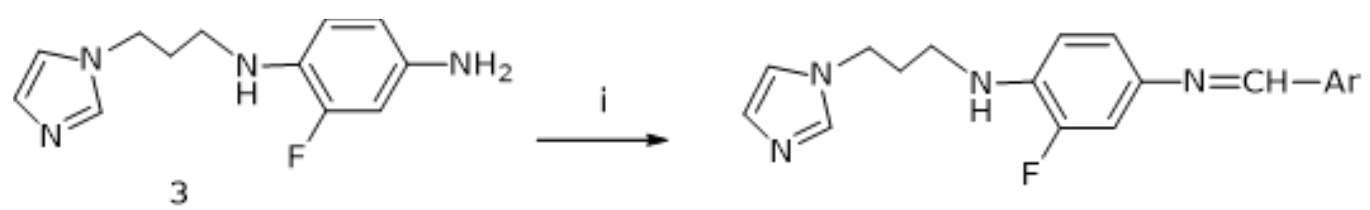

$17 \mathrm{a}-\mathrm{d}$

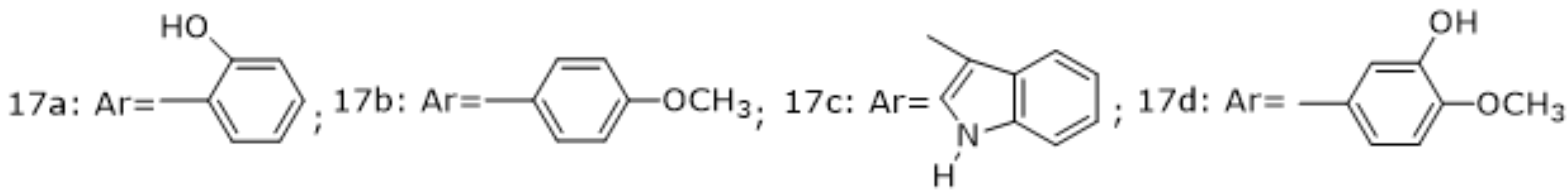

Scheme 4. i: suitable aldehyde, ethanol, reflux, $3 \mathrm{~h}$.

The FT-IR spectra of 1,3-thiazolidinones displayed a peak in the wavenumber value of the thiocarbonyl absorption from $1227-1287 \mathrm{~cm}^{-1}$ to $1701-1731 \mathrm{~cm}^{-1}$ which represents characteristic carbonyl band at the position 5 of 1,3-thiazolidinone ring. The disappearances of two $\mathrm{NH}$ signals and the appearance of $\mathrm{CH}_{2}$ protons of 1,3-thiazolidin-5-one ring at 4.06-4.79 ppm in the ${ }^{1} \mathrm{H}$ NMR spectra supported the formation of 1,3-thiazolidinones $\mathbf{6}, \mathbf{1 1}$, and $\mathbf{1 6 .}$

These products gave mass spectral and elemental analysis data corresponding to the proposed structures. ${ }^{13} \mathrm{C}$ NMR spectra of these compounds $(\mathbf{6}, \mathbf{1 1}$, and 16) exhibited peaks for $\mathrm{C}-4$ and C-5 carbons at 32.02-33.23 ppm and 167.41-181.75 ppm, respectively which is consistent with formation of 1,3-thiazolidinone ring. The synthesis of esters $(\mathbf{7}, \mathbf{1 2}, \mathbf{1 9}$, and $\mathbf{2 8})$ was achieved by the condensation of $\mathbf{1}, \mathbf{3}, \mathbf{1 8}$, and $\mathbf{2 7}$ with ethylbromoacetate in the presence of triethyl amine in THF under conventional, MW and ultrasonic conditions. Under MW irradiation, maximum yield and minimum reaction time was specified as $50^{\circ} \mathrm{C}, 80 \mathrm{~W}$ with the yields varying between $94-100 \%$. On the other hand, sonication of the reaction mixtures resulted in a bit better yields, while reaction times of both methods (MW and US) were nearly the same.

In the ${ }^{1} \mathrm{H}$ NMR spectra, the shift in the peak of $\mathrm{NH}_{2}$ from 4.49-4.54 ppm to 8.05-9.11 ppm attributed to $\mathrm{NH}$ proton and the presence additional signals due to ester function at the appropriate chemical shift values verified the condensation. The treatment of 7, 12, and 19 and 28 with hydrazine hydrate afforded the corresponding acetohydrazides (8, 13, 20 and 29) which was established by the appearance of $\mathrm{NHNH}_{2}$ stretching bands of hydrazide function in the FTIR spectrum. In ${ }^{1} \mathrm{H}$ NMR, the appearance of $\mathrm{NH}_{2}$ and $\mathrm{NH}$ protons and disappearance of signals for $\mathrm{CH}_{3}$ and two $\mathrm{CH}_{2}$ protons confirmed the formation of the target products $(\mathbf{8}, \mathbf{1 3}, \mathbf{2 0}$, and 29). 
<smiles>CC#CC(=O)OCC(=O)CNCCN1CCOCC1</smiles>

Scheme 5. i: Ethylbromoacetate, triethylamine, ii: $\mathrm{NH}_{2} \mathrm{NH}_{2}$, iii: phenylisothiocyanate, iv: 2-Bromo-1-(4chlorophenyl)ethanone, $\mathrm{NaOAc}$, v: $\mathrm{NaOH}(\mathrm{aq})$, vi: 6-aminopenicillanic acid, formaldehyde, $\mathrm{HCl}$, vii: suitable aldehyde, r.t, 3 h.
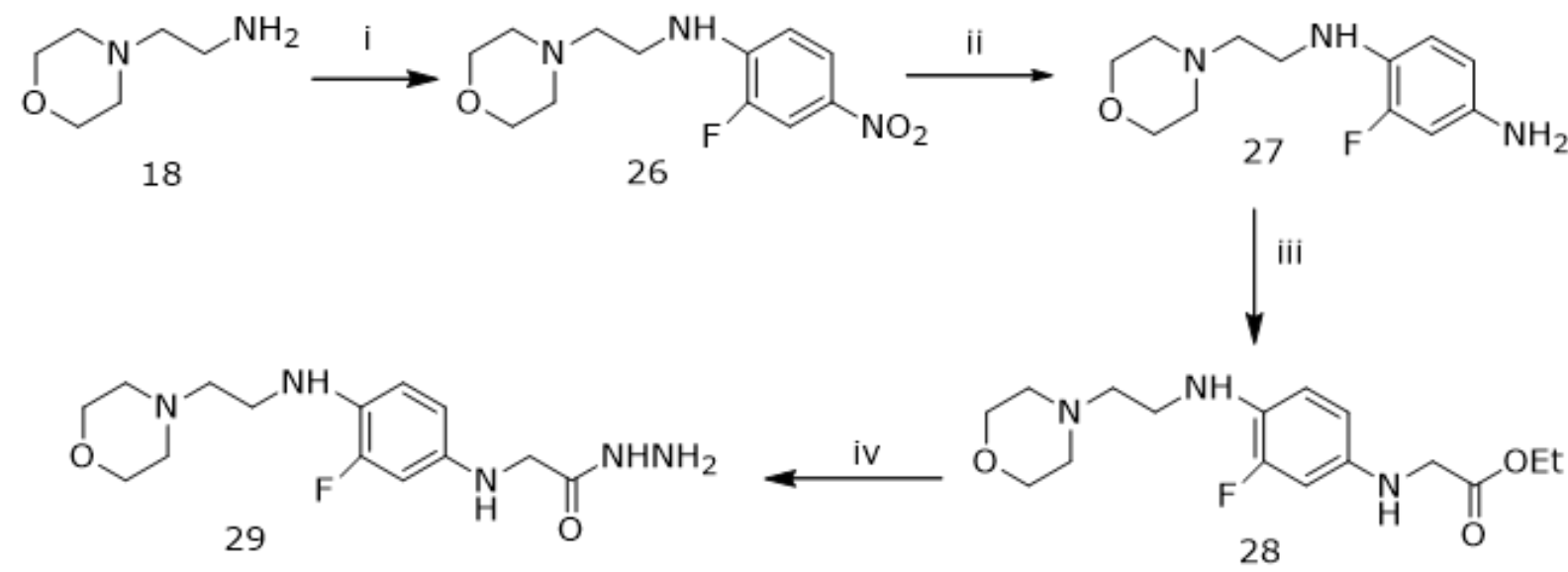

Scheme 6: i: 3,4-difluoronitrobenzene, ii: $\mathrm{NH}_{2} \mathrm{NH}_{2}, \mathrm{Pd} / \mathrm{C}$, iii: ethyl bromoacetate, triethylamine, iv: $\mathrm{NH}_{2} \mathrm{NH}_{2}$.

The synthesis of 1,2,4-triazole (23) was carried out from the intramolecular cyclisation of thioamide $\mathbf{2 1}$ in the basic media. The reaction was carried out in water as a non-toxic solvent under thermal, microwave and ultrasonic conditions. MW and US mediated techniques led to higher yields; however, the virtual effect of MW assistance and sonication was on reaction times 
Demirci. JOTCSA. 2018; 5(2): 393-414.

changing from $3 \mathrm{~h}$ to 5-15 min with increased yields from $79 \%$ to $89 \%$ (for MW) $-80 \%$ (for US). Among the latter two methods, the microwave irradiation resulted in a bit better reaction yield for this condensation. The supplemental support verifying the structures of these compounds was obtained by LC-MS spectrum, and these compounds gave elemental analysis data confirming the proposed structures.

The 1,2,4-triazole 23 was then subjected to a one pot three component condensation with $\mathrm{R}(+)$ 6-aminopenicillanic acid to yield compound $\mathbf{2 4}$, the structure of which was verified by using spectroscopic techniques. The synthesis of imine compounds, $\mathbf{1 7} \mathbf{a}-\mathbf{d}$ and $\mathbf{2 5 a} \mathbf{a} \mathbf{b}$ was performed from the reaction of hydrazides $\mathbf{3}$ and $\mathbf{2 0}$ with the corresponding aldehydes namely, salicylaldehyde, anisaldehyde, vanillin and indol-3-carbaldehyde which were clearly evident with the disappearance of $\mathrm{NH}_{2}$ signals in the ${ }^{1} \mathrm{H}$ NMR spectra. Instead, new signal due to azomethine proton was recorded at 8.35-8.52 ppm. The imine-carbon resonated at 153.29-141.22 ppm in the ${ }^{13} \mathrm{C}$ NMR spectra.

Other signals originated arylidene moiety were recorded at the expected chemical shift values. Furthermore, the mass spectral data and elemental analysis results are in accordance with their structures. The proton NMR observations revealed that, two singlets belonging to two NH protons were disappeared with the formation of the triazole. 
Table 1: Physical parameters for the synthesis of new compounds by conventional, microwave and ultrasound mediated methods.

\begin{tabular}{|c|c|c|c|c|c|c|c|c|c|}
\hline \multirow[t]{2}{*}{ Comp No } & \multicolumn{3}{|c|}{ Conventional Method } & \multicolumn{3}{|c|}{ Microwave Irradiated Method } & \multicolumn{3}{|c|}{ Ultrasound Irradiated Method } \\
\hline & Time(h) & Temp $\left({ }^{\circ} \mathrm{C}\right)$ & Yield(\%) & Time (min) & Pow.(W) & Yield(\%) & Time(min) & Pow.(kHz) & Yield(\%) \\
\hline 2 & 10 & $\mathrm{rt}$ & 62 & 10 & 100 & 81 & 30 & 45 & 83 \\
\hline 3 & 12 & 118 & 84 & 30 & 150 & 94 & 35 & 70 & 98 \\
\hline 4 & 12 & rt & 81 & 15 & 150 & 97 & 15 & 60 & 94 \\
\hline 5 & 16 & reflux & 85 & 15 & 150 & 97 & 18 & 60 & 95 \\
\hline 6 & 18 & reflux & 60 & 12 & 100 & 88 & 15 & 50 & 30 \\
\hline 7 & 24 & $\mathrm{rt}$ & 80 & 18 & 80 & 100 & 20 & 40 & 100 \\
\hline 8 & 5 & reflux & 96 & 14 & 200 & 100 & 16 & 40 & 100 \\
\hline $9 a$ & 12 & $\mathrm{rt}$ & 46 & 15 & 150 & 79 & 15 & 60 & 77 \\
\hline $9 b$ & 16 & rt & 83 & 15 & 150 & 96 & 15 & 60 & 96 \\
\hline 10 & 18 & reflux & 86 & 15 & 150 & 99 & 18 & 60 & 99 \\
\hline 11 & 16 & reflux & 75 & 12 & 100 & 85 & 15 & 50 & 30 \\
\hline 12 & 16 & $\mathrm{rt}$ & 89 & 18 & 80 & 94 & 20 & 40 & 100 \\
\hline 13 & 5 & rt & 95 & 14 & 200 & 100 & 18 & 70 & 100 \\
\hline 14 & 20 & rt & 60 & 15 & 150 & 92 & 15 & 65 & 89 \\
\hline 15 & 17 & reflux & 84 & 15 & 150 & 94 & 18 & 60 & 98 \\
\hline 16 & 18 & reflux & 69 & 12 & 100 & 97 & 15 & 50 & 96 \\
\hline $17 a$ & 3 & reflux & 73 & 8 & 100 & 98 & 5 & 70 & 100 \\
\hline $17 b$ & 3 & reflux & 55 & 8 & 100 & 76 & 5 & 70 & 99 \\
\hline $17 \mathrm{c}$ & 3 & reflux & 99.5 & 8 & 100 & 100 & 5 & 70 & 100 \\
\hline $17 d$ & 3 & reflux & 58 & 8 & 100 & 90 & 5 & 70 & 100 \\
\hline 19 & 24 & rt & 65 & 18 & 80 & 100 & 20 & 40 & 100 \\
\hline 20 & 5 & rt & 99.5 & 14 & 200 & 100 & 15 & 70 & 100 \\
\hline 21 & 12 & rt & 46 & 15 & 150 & 89 & 15 & 70 & 87 \\
\hline 22 & 18 & reflux & 65 & 15 & 150 & 89 & 18 & 60 & 88 \\
\hline 23 & 3 & rt & 79 & 12 & 200 & 89 & 15 & 70 & 80 \\
\hline 24 & 3 & rt & 65 & 5 & 100 & 80 & 10 & 40 & 82 \\
\hline $25 a$ & 3 & reflux & 75 & 8 & 100 & 90 & 5 & 70 & 100 \\
\hline $25 b$ & 3 & reflux & 98 & 8 & 100 & 90 & 5 & 70 & 100 \\
\hline 26 & 10 & $\mathrm{rt}$ & 60 & 8 & 100 & 92 & 5 & 70 & 90 \\
\hline 27 & 12 & reflux & 75 & 8 & 150 & 95 & 5 & 70 & 98 \\
\hline 28 & 24 & $\mathrm{rt}$ & 79 & 18 & 80 & 97 & 20 & 40 & 100 \\
\hline 29 & 5 & reflux & 79 & 14 & 200 & 100 & 18 & 70 & 100 \\
\hline
\end{tabular}




\section{CONCLUSIONS}

In this study, we reported the synthesis of some new hybrid molecules containing several heterocyclic units with conventional, microwave irradiated and ultrasound-promoted procedures. Four imidazole derivatives and, two morpholine-derived Schiff bases were synthesised. Antimicrobial activities screening studies were also performed. Most of the newly synthesised compounds exhibited good to moderate activities on some of the test microorganisms. Of these, the compounds containing a fluoroquinolone unit linked to the 1-7 and 12-17 scaffold via a methylene linkage exhibited excellent activity on the test bacteria. Compounds 17c, 24 and 25 which are hybrid compounds with a $\beta$-lactam unit, were found to exhibit microbial activity on the Mycobacterium smegmatis (Ms) respectively.

\section{ACKNOWLEDGMENTS}

Thanks are expressed to Prof. Dr. Sengul Alpay Karaoglu for antimicrobial studies. The support provided by Giresun University, BAP, Turkey (Ref. No. Fen-Bap-A-200515-88 and Fen-Bap-A-140316-24) are gratefully acknowledged.

\section{REFERENCES}

1. Minbiole KPC, Jennings MC, Ator LE, Black JW, Grenier MC, LaDow JE, et al. From antimicrobial activity to mechanism of resistance: the multifaceted role of simple quaternary ammonium compounds in bacterial eradication. Tetrahedron 2016;72:3559-66.

2. Yang H, Wang H-W, Zhu T-W, Yu L-M, Chen J-W, Wang L-X, et al. Syntheses and antibacterial activity of soluble 9-bromo substituted indolizinoquinoline-5,12-dione derivatives. Eur J Med Chem 2017;127:166-73.

3. Kawai T, Kazuhiko I, Takaya N, Yamaguchi Y, Kishii R, Kohno Y, et al. Sulfonamide-based non-alkyne LpxC inhibitors as Gram-negative antibacterial agents. Bioorg Med Chem Lett 2017;27:1045-9.

4. Yan S, Song L, Luan S, Xin Z, Du S, Shi H, et al. A hierarchical polymer brush coating with dual-function antibacterial capability. Colloids Surfaces B Biointerfaces 2017;150:250-60.

5. Alagumuthu M, Arumugam S. Molecular docking, discovery, synthesis, and pharmacological properties of new 6-substituted-2-3-phenoxyphenyl. -4-phenyl quinoline derivatives; an approach to developing potent DNA gyrase inhibitors/antibacterial agents. Bioorg Med Chem 2017;25:144855. 
6. Jeankumar VU, Renuka J, Santosh P, Soni V, Sridevi JP, Suryadevara P, et al. Thiazoleaminopiperidine hybrid analogues: Design and synthesis of novel Mycobacterium tuberculosis GyrB inhibitors. Eur J Med Chem 2013;70:143-53.

7. War JA, Srivastava SK, Srivastava SD. Design, synthesis and DNA-binding study of some novel morpholine linked thiazolidinone derivatives. SpectrochimActa Part A MolBiomolSpectrosc 2017;173:270-8.

8. Padmavathi V, PremaKumari C, Venkatesh BC, Padmaja A. Synthesis and antimicrobial activity of amido linked pyrrolyl and pyrazolyl-oxazoles, thiazoles and imidazoles. Eur J Med Chem 2011;46:5317-26.

9. Chen W, Deng X-Y, Li Y, Yang L-J, Wan W-C, Wang X-Q, et al. Synthesis and cytotoxic activities of novel hybrid 2-phenyl-3-alkylbenzofuran and imidazole/triazole compounds. Bioorg Med Chem Lett 2013;23:4297-302.

10. Wang K, Xu W, Liu Y, Zhang W, Wang W, Shen J, et al. Design and synthesis of imidazole and triazole derivatives as LP-PLA2 inhibitors and the unexpected discovery of highly potent quaternary ammonium salts. Bioorg Med Chem Lett 2013;23:1187-92.

11. Yurttaş L, Duran M, Demirayak Ş, Gençer HK, Tunalı Y. Synthesis and initial biological evaluation of substituted 1-phenylamino-2-thio-4,5-dimethyl-1H-imidazole derivatives. Bioorg Med Chem Lett 2013;23:6764-8.

12. Wen S-Q, Jeyakkumar P, Avula SR, Zhang L, Zhou C-H. Discovery of novel berberineimidazoles as safe antimicrobial agents by down regulating ROS generation. Bioorg Med Chem Lett 2016;26:2768-73.

13. Rathore A, Sudhakar R, Ahsan MJ, Ali A, Subbarao N, Jadav SS, et al. In vivo antiinflammatory activity and docking study of newly synthesized benzimidazole derivatives bearing oxadiazole and morpholine rings. BioorgChem 2017;70:107-17.

14. Tereshchenko AD, Myronchuk JS, Leitchenko LD, Knysh I V., Tokmakova GO, Litsis OO, et al. Synthesis of 3-oxadiazolyl/triazolyl morpholines: Novel scaffolds for drug discovery. Tetrahedron 2017;73:750-7.

15. Surendra Kumar R, Moydeen M, Al-Deyab SS, Manilal A, Idhayadhulla A. Synthesis of new morpholine-connected pyrazolidine derivatives and their antimicrobial, antioxidant, and cytotoxic activities. Bioorg Med Chem Lett 2017;27:66-71. 
Demirci. JOTCSA. 2018; 5(2): 393-414.

16. Doan P, Karjalainen A, Chandraseelan JG, Sandberg O, Yli-Harja O, Rosholm T, et al. Synthesis and biological screening for cytotoxic activity of $\mathrm{N}$-substituted indolines and morpholines. Eur J Med Chem 2016;120:296-303.

17. Gadekar PK, Roychowdhury A, Kharkar PS, Khedkar VM, Arkile M, Manek H, et al. Design, synthesis and biological evaluation of novel azaspiro analogs of linezolid as antibacterial and antitubercular agents. Eur J Med Chem 2016;122:475-87.

18. Micheli F, Cremonesi S, Semeraro T, Tarsi L, Tomelleri S, Cavanni P, et al. Novel morpholine scaffolds as selective dopamine DA. D3 receptor antagonists. Bioorganic Med Chem Lett $2016 ; 26: 1329-32$.

19. Zhao Z, Pissarnitski DA, Josien HB, Bara TA, Clader JW, Li H, et al. Substituted 4morpholine N-arylsulfonamides as ??-secretase inhibitors. Eur J Med Chem 2016;124:36-48.

20. Desai NC, Rajpara KM, Joshi V V. Microwave induced synthesis of fluorobenzamides containing thiazole and thiazolidine as promising antimicrobial analogs. J Fluor Chem 2013;145:102-11.

21. Zhao Z, Shi Z, Liu M, Liu X. Microwave-assisted synthesis and in vitro antibacterial activity of novel steroidal thiosemicarbazone derivatives. Bioorg Med Chem Lett 2012;22:7730-4.

22. Mamaghani M, Loghmanifar A, Taati MR. An efficient one-pot synthesis of new 2-imino-1,3thiazolidin-4-ones under ultrasonic conditions. UltrasonSonochem 2011;18:45-8.

23. Hossein Nia R, Mamaghani M, Tabatabaeian K, Shirini F, Rassa M. An expeditious regioselective synthesis of novel bioactive indole-substituted chromene derivatives via one-pot three-component reaction. Bioorganic Med Chem Lett 2012;22:5956-60.

24. Martinez-Guerra E, Gude VG. Synergistic effect of simultaneous microwave and ultrasound irradiations on transesterification of waste vegetable oil. Fuel 2014;137:100-8.

25. Mahmoodi NO, Shoja S, Tabatabaeian K, Sharifzadeh B. Ultrasound-promoted one-pot fivecomponents synthesis of biologically active novel bis6-alkyl or phenyl-2-phenylpyrimidine-4-yl. oxy. alkane or methyl benzene derivatives. UltrasonSonochem 2015;23:31-6.

26. Chen B-H, Li J-T, Chen G-F. Efficient synthesis of 2,3-disubstituted-2,3-dihydroquinazolin$41 \mathrm{H}$. -ones catalyzed by dodecylbenzenesulfonic acid in aqueous media under ultrasound irradiation. UltrasonSonochem 2015;23:59-65.

27. Nyborg WL. Biological effects of ultrasound: Development of safety guidelines. Part II: General review. Ultrasound Med Biol 2001;27:301-33. 
Demirci. JOTCSA. 2018; 5(2): 393-414.

28. Mentese MY, Bayrak H, Uygun Y, Mermer A, Ulker S, Karaoglu SA, et al. Microwave assisted synthesis of some hybrid molecules derived from norfloxacin and investigation of their biological activities. Eur J Med Chem 2013;67:230-42.

29. Ceylan S, Bektas H, Bayrak H, Demirbas N, Alpay-Karaoglu S, Ülker S. Syntheses and biological activities of new hybrid molecules containing different heterocyclic moieties. Arch Pharm Weinheim. 2013;346:743-56.

30. Mentese M, Demirci S, Ozdemir SB, Demirbas A, Ulker S, Demirbas N. Microwave assisted synthesis and antimicrobial activity evaluation of new heterofunctionalizednorfloxacine derivatives. Lett Drug Des Discov 2016;13:1076-90.

31. Weatherburn MW. Phenol-hypochlorite reaction for determination of ammonia. Anal Chem $1967 ; 39: 971-4$. 